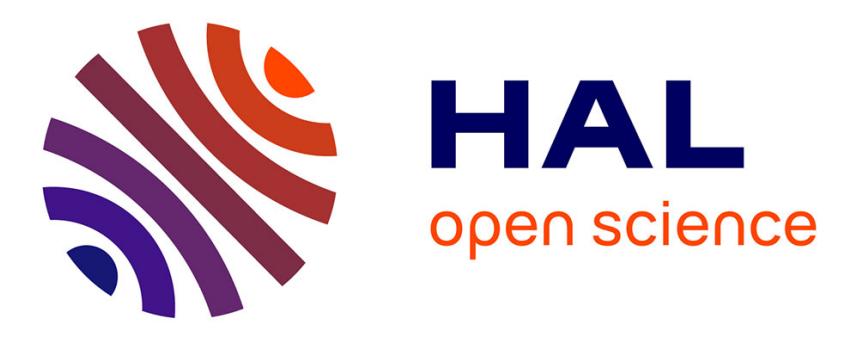

\title{
The effects of ball milling and the addition of blended elemental aluminium on the densification of TiH2 power
}

E. Schumann, Jean-François Silvain, Jean-Louis Bobet, Matthieu Bardet, Yongfeng Lu, Andrei Kotousov, Mélanie Lamirand-Majimel

\section{- To cite this version:}

E. Schumann, Jean-François Silvain, Jean-Louis Bobet, Matthieu Bardet, Yongfeng Lu, et al.. The effects of ball milling and the addition of blended elemental aluminium on the densification of TiH2 power. Materials Chemistry and Physics, 2016, 173, pp.106-116. 10.1016/j.matchemphys.2016.01.045 . hal-01286000

\section{HAL Id: hal-01286000 https://hal.science/hal-01286000}

Submitted on 2 Feb 2021

HAL is a multi-disciplinary open access archive for the deposit and dissemination of scientific research documents, whether they are published or not. The documents may come from teaching and research institutions in France or abroad, or from public or private research centers.
L'archive ouverte pluridisciplinaire HAL, est destinée au dépôt et à la diffusion de documents scientifiques de niveau recherche, publiés ou non, émanant des établissements d'enseignement et de recherche français ou étrangers, des laboratoires publics ou privés. 


\title{
The effects of ball milling and the addition of blended elemental aluminium on the densification of $\mathrm{TiH}_{2}$ power
}

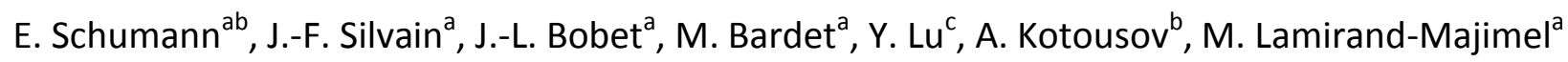

${ }^{a}$ Institut de Chimie de la Matire Condensée de Bordeaux (ICMCB-CNRS), 87 Avenue du Dr Schweitzer, F33608, Pessac, France

${ }^{b}$ The University of Adelaide, North Terrace, Adelaide, South Australia, 5005, Australia

${ }^{c}$ Department of Electrical Engineering, University of Nebraska - Lincoln, Lincoln, NE, 68588-0511, USA

\begin{abstract}
Powder production and sintering processes of titanium powder metallurgy are studied in order to reduce the cost of manufacturing titanium parts. The direct sintering of $\mathrm{TiH}_{2}$ simplifies powder processing and helps densification during sintering. The effects of ball milling have been shown to improve the dehydrogenation of $\mathrm{TiH}_{2}$, which during sintering, causes the earlier dissolution of the oxide layer surrounding the solid titanium particles, allowing solid diffusion to occur earlier. The combined effect of reduced particle size and increased dehydrogenation of ball milled $\mathrm{TiH}_{2}$ are studied here during sintering, in order to understand their roles during densification. $\mathrm{TiH}_{2}$ ball milled for various durations is vacuum hot press sintered at $700-900{ }^{\circ} \mathrm{C}$. The density, microstructure and hardness of the fabricated titanium specimens are also studied. The effects of ball milled powder on the introduction of blended elemental aluminium are studied in comparison with a commercial titanium powder. The increase in ball milling duration of $\mathrm{TiH}_{2}$ powders to reduce particle size causes faster densification and dehydrogenation, with a finer uniform microstructure. When using fine ball milled powder with aluminium, the formation of Kirkendall pores through the interaction of titanium and liquid aluminium is worsened.
\end{abstract}

Keywords : Metals ; Powder metallurgy ; Sintering ; Differential scanning calorimetry ; Energy dispersive analysis of X-rays.

\section{Introduction}

Titanium has an excellent specific strength and corrosion resistance at high operating temperatures. However, the cost of titanium is 15-50 times that of conventional engineering materials such as steel [1]. Thus, the application of titanium is restricted to high specification applications which justify the cost of titanium. The high cost of titanium production is linked to its affinity for atmospheric contaminants, meaning the refinement process used (the Krolls process) has multiple steps and is not continuous [2]. Firstly, oxygen is removed from titanium ore by chlorination at $1000{ }^{\circ} \mathrm{C}$ to form $\mathrm{TiCl}_{4}$, then this is reduced using liquid $\mathrm{Mg}$ in an inert gas atmosphere at temperatures between 800 and $850^{\circ} \mathrm{C}$ (Equation (2.1)) [3].

$$
2 \mathrm{Mg}_{(l)}+\mathrm{TiCl}_{4(g)} \rightarrow 2 \mathrm{MgCl}_{2}+\mathrm{Ti}_{(\text {solidsponge })}\left[\mathrm{T}=800-850^{\circ} \mathrm{C}\right]
$$

The Krolls process produces porous globular pieces of titanium called sponge, which is then conventionally arc melted several times to form dense material. To reduce the cost of titanium, powder metallurgy has been investigated in various forms for net shape part production to reduce billet processing and machining costs. 
Current research focuses on the general improvement of conventional sintering processes, such as cold press (CP) and sinter, and the use of different starting powders, such as mechanically alloyed, hydride-dehydride (HDH) powders and $\mathrm{TiH}_{2}$ powders [4], [5], [6], [7], [8], [9], [10]. The methods of refinement and powder production are also studied in order to reduce the cost [11], [12], [13]. However, the process still uses multiple stages and is expensive. Significant research efforts are currently focused on improved techniques such as the use of thermo-hydrogen processing, liquid phase sintering (LPS) and advanced sintering techniques such as spark plasma sintering, microwave sintering and selective laser melting [14]. Except for thermo-hydrogen processing, which has been shown to simplify powder processing and enhance sintering [15], the employment of advanced techniques adds complexity and cost to titanium parts.

The use of hydrogen as a temporary alloying element in titanium facilitates processing [16], enabling the production of a fine $\mathrm{TiH}_{2}$ powder through ball milling. $\mathrm{TiH}_{2}$ sponge is easily milled using ball milling to form $\mathrm{TiH}_{2}$ powders with controlled granulometry and high defect density that has been shown to help densification. The direct sintering of $\mathrm{TiH}_{2}$ has been shown to improve densification through the dehydrogenation process which takes place during sintering [4], [5], [17], [18]. The dehydrogenation of $\mathrm{TiH}_{2}$ that occurs during sintering helps densification by leaving a freshly dehydrogenated surface [9], [19]. During sintering of titanium powder, densification begins to accelerate at approximately $700{ }^{\circ} \mathrm{C}$ due to the dissolution of the oxide layer surrounding the titanium particles [20], allowing solid/solid diffusion across particles. Sintering $\mathrm{TiH}_{2}$ helps to lower the temperature at which the oxide layer is reduced. Dehydrogenation begins upon heating under a vacuum $\left(10^{-1}\right.$ to $\left.10^{-2} \mathrm{mbar}\right)$ at approximately $400{ }^{\circ} \mathrm{C}$ [21], and initiates the reduction of the oxide layer [18], which otherwise dissolves at approximately $600{ }^{\circ} \mathrm{C}\left[22\right.$ ]. $\mathrm{The}^{\mathrm{TiO}_{2}}$ layer on the surface of the particles is reduced when it interacts with hydrogen liberated by the dehydrogenation of $\mathrm{TiH}_{2}$ (Equation 2.2) [23]:

$$
\mathrm{TiO}_{2(s)}+2 \mathrm{H}_{2(\mathrm{~g})} \rightarrow \mathrm{Ti}_{(s)}+2 \mathrm{H}_{2} \mathrm{O}_{(\mathrm{g})}
$$

Furthermore, diffusion is enhanced in ball milled powder because of the high defect density caused by the mechanical work of brittle $\mathrm{TiH}_{2}$ [5], which also exists in $\mathrm{HDH}$ powder, albeit reduced by the dehydrogenation heat treatment it undergoes.

Studies of the effect of ball milling on the dehydrogenation of $\mathrm{TiH}_{2}$ show that it increases the rate of desorption. Comparison of powder produced by mechanical milling of $\mathrm{TiH}_{2}$ with powder produced by hydrogen absorption by Zhang and Kisi [24] shows an increase in desorption kinetic in milled powders. The reduction of powder size through ball milling was shown to reduce the onset of dehydrogenation by Bhosle et al. [25]. The evolution of hydrogen from $\mathrm{TiH}_{2}$ is shown to be controlled by detrapping of hydrogen [26], while further barriers for the evolution of hydrogen are the diffusion through the lattice and grain boundaries. The dehydrogenation of $\mathrm{TiH}_{2}$ has been studied by thermal analyses (differential scanning calorimetry [DSC], thermo gravimetric analysis [TGA]) and X-ray diffraction (XRD). Study of the effects of heating on desorption of hydrogen shows that slow heating rates lower the onset of desorption, and that the rate of desorption increases with isothermal temperature. Analysis of the ball milled $\mathrm{TiH}_{2}$ powders in these studies has shown the reduction of particle size and the reduction of crystallite size observed by scanning electron microscopy (SEM) and XRD respectively. Thus, faster dehydrogenation is explained by (i) smaller particles having a greater surface area, giving a faster surface evolution from the particle bulk, and (ii) the high defect density allows faster diffusion paths. Because the dehydrogenation of $\mathrm{TiH}_{2}$ during sintering increases densification, and because the kinetic of desorption is increased by ball milling, the densification can be controlled by ball milling. Current research efforts show that $\mathrm{TiH}_{2}$ improves sintering by conventional methods [9], [17], [19], [23], but have not investigated the potential of particle size reduction by ball milling to reduce temperatures, nor the limitations imposed by the dehydrogenation process. The characteristics of ball milled $\mathrm{TiH}_{2}$ are studied here in order to understand their potential improvement to and limitations on sintering. 
Because of the common use of blended elemental aluminium with titanium in the production of titanium alloys, it was also necessary to study the effect of the use of $\mathrm{TiH}_{2}$ with the addition of aluminium. Because of the low melting point of aluminium, it will constitute a liquid phase during sintering, and because of the reactivity of aluminium with titanium (i.e. the formation of intermetallics), it causes reactive LPS. Where generally the effects of LPS are beneficial to the densification of parts, aluminium was shown to cause swelling due to the migration of aluminium during diffusion causing Kirkendall pores [27]. The diffusion that occurs between titanium and liquid aluminium can be schematically described as in Fig. 1 . The richer aluminium phase $\left(\mathrm{TiAl}_{3}\right)$ forms first, while aluminium diffuses through $\mathrm{TiAl}_{3}$ to the reaction front [28] which causes the formation of porosity (i.e. Kirkendall pores) due to the motion of mass. Then titanium diffuses through $\mathrm{TiAl}_{3}$ to form phases richer in titanium, until eventually homogenisation to a single compound occurs. The Kirkendall effect is so predominant in reactive LPS of titanium and aluminium that it has even been used to create an open porous Ti-Al microstructure [29] to use as a permeable material. Mechanical milling of blended titanium and aluminium powders is often used before sintering to begin the reaction and reduce pores formed by the Kirkendall effect [4].

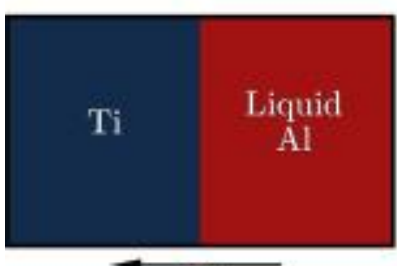

$\widehat{\mathrm{Al}}$ diffuses
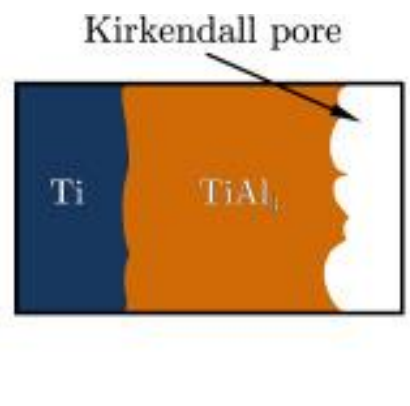

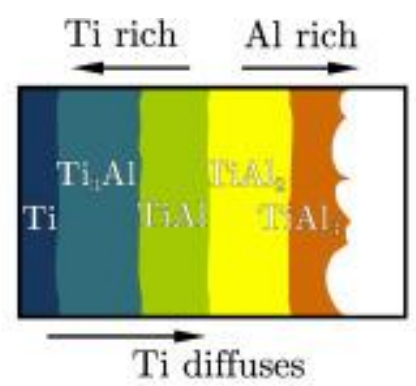

Ti diffuses

Fig. 1. Diffusion between liquid Aluminium and Titanium.

The formation of intermetallics occurs at the surface of the titanium particles and therefore depends on the size of the particles. Savitskii and Burtsev [30] found that by increasing the titanium particle size above $45 \mu \mathrm{m}$, the growth of the intermetallic layer on the titanium particles caused the specimen to swell. The effect of LPS is largely controlled by the diffusion between the liquid and solid phases at the solid particle surface, and the effect on densification of reduced particle size, created by ball milling, has not yet been studied.

Table 1

Mode particle size by volume of $\mathrm{TiH}_{2}$ powders ball milled for 5-180 min.

\begin{tabular}{ll}
\hline Duration $(\min )$ & Mode particle size $(\mu \mathrm{m})$ \\
\hline 5 & 6.6 \\
10 & 2.2 \\
30 & 1.9 \\
60 & 1.7 \\
180 & 1.0 \\
\hline
\end{tabular}

While the benefit of directly sintering $\mathrm{TiH}_{2}$ is known, there is not sufficient understanding of the capability of this technique to reduce the required sintering parameters, which relates to the global objective to reduce the cost of titanium production. Furthermore, previous studies of sintering $\mathrm{TiH}_{2}$ have found complete dehydrogenation [4], [6], [9], [10]: the required sintering parameters for complete dehydrogenation are not clearly known to date. Therefore, the effect of (i) the duration of ball milling on the densification and (ii) the dehydrogenation during induction hot press sintering at a low range of temperatures $\left(700-900^{\circ} \mathrm{C}\right)$ will also be studied. 
The effect of titanium particle size on the reactive LPS that occurs with added blended elemental aluminium is studied. The reaction is studied with a range of aluminium concentrations and temperatures to study the densification and phase formation during sintering of fine ball milled $\mathrm{TiH}_{2}$ powders and will be compared with a larger commercial powder. Our main objective is to show that the use of ball milled $\mathrm{TiH}_{2}$ powder could improve sintering densification leading to the reduction of sintering temperatures and durations, and then reducing the cost of titanium part production.

\section{Experimental}

\subsection{Materials}

For this study, commercial titanium sponge (Strem Chemicals 99.8\%, reference 93-2268), commercial titanium powder (Alfa Aesar 99.5\%, reference 042624, mean particle size of $44 \mu \mathrm{m}$ ), and commercial aluminium powder (Poudre Emillon 99.97\%, reference F3731, with a mean particle size of $12 \mu \mathrm{m}$ ), were used. Commercial titanium sponge is hydrogenated at $500{ }^{\circ} \mathrm{C}$ for $3 \mathrm{~h}$ under 40 bar of hydrogen to form $\mathrm{TiH}_{2}$. The formation of $\mathrm{TiH}_{2}$ was confirmed by XRD pattern matching. The $\mathrm{TiH}_{2}$ sponge was milled for $5-180$ min in a Fritsch planetary ball mill Pulverisette 5 at $250 \mathrm{rpm}$. A stainless steel vial was filled with $8 \mathrm{~g}$ of $\mathrm{TiH}_{2}$ and 17 hardened steel balls of $10 \mathrm{~mm}$ in diameter. The vial was purged of air up to $10^{-2} \mathrm{~Pa}$ and filled with 10 bar of hydrogen, and were recharged every $60 \mathrm{~min}$ (to account for possible leaks). All the handling was performed in an argon glove box.
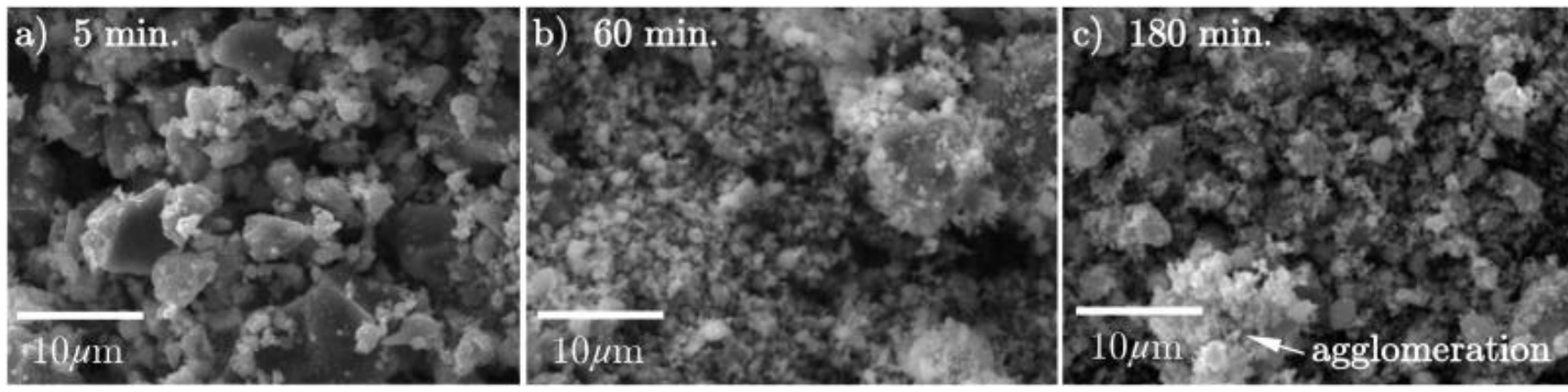

Fig. 2. SEM micrographs of $\mathrm{TiH}_{2}$ powder ball milled for (a) 5, (b) 60 and (c) 180 min (from left to right).

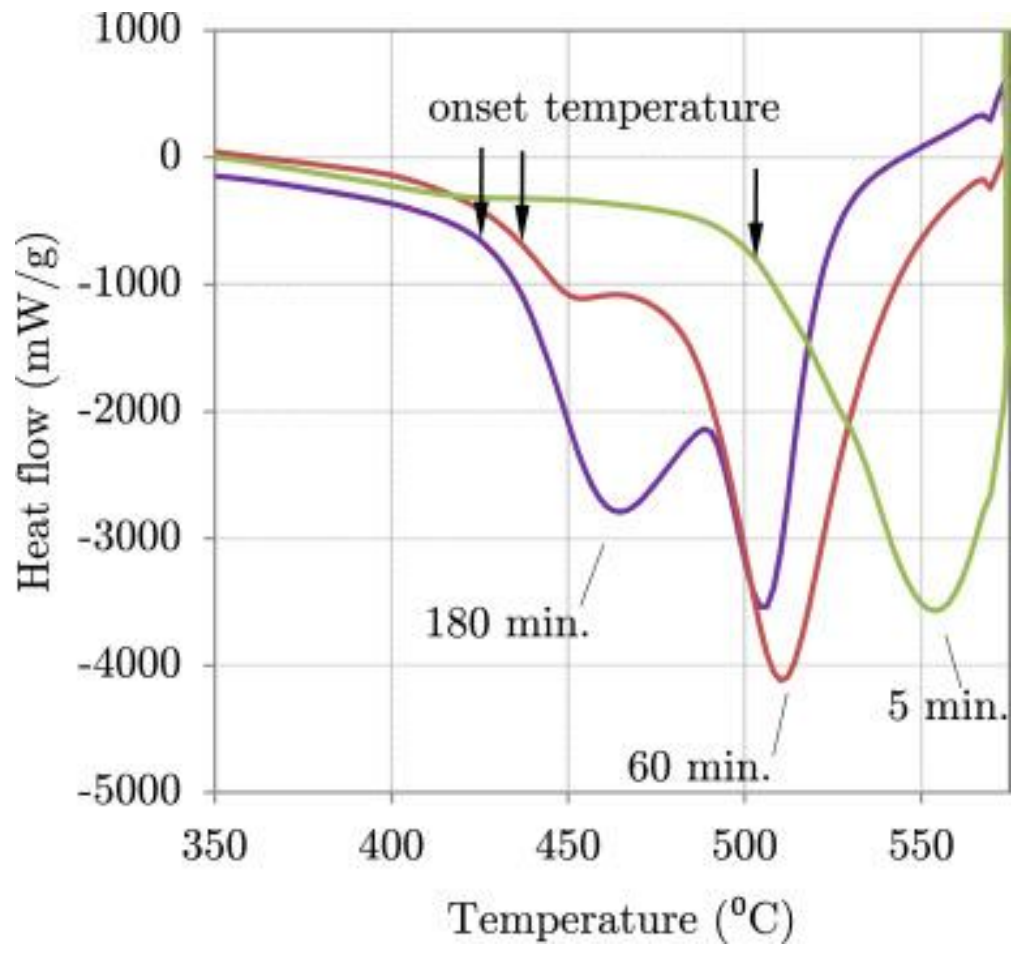


Fig. 3. DSC of $\mathrm{TiH}_{2}$ powder ball milled for 5, 60, and 180 min showing the desorption of hydrogen.

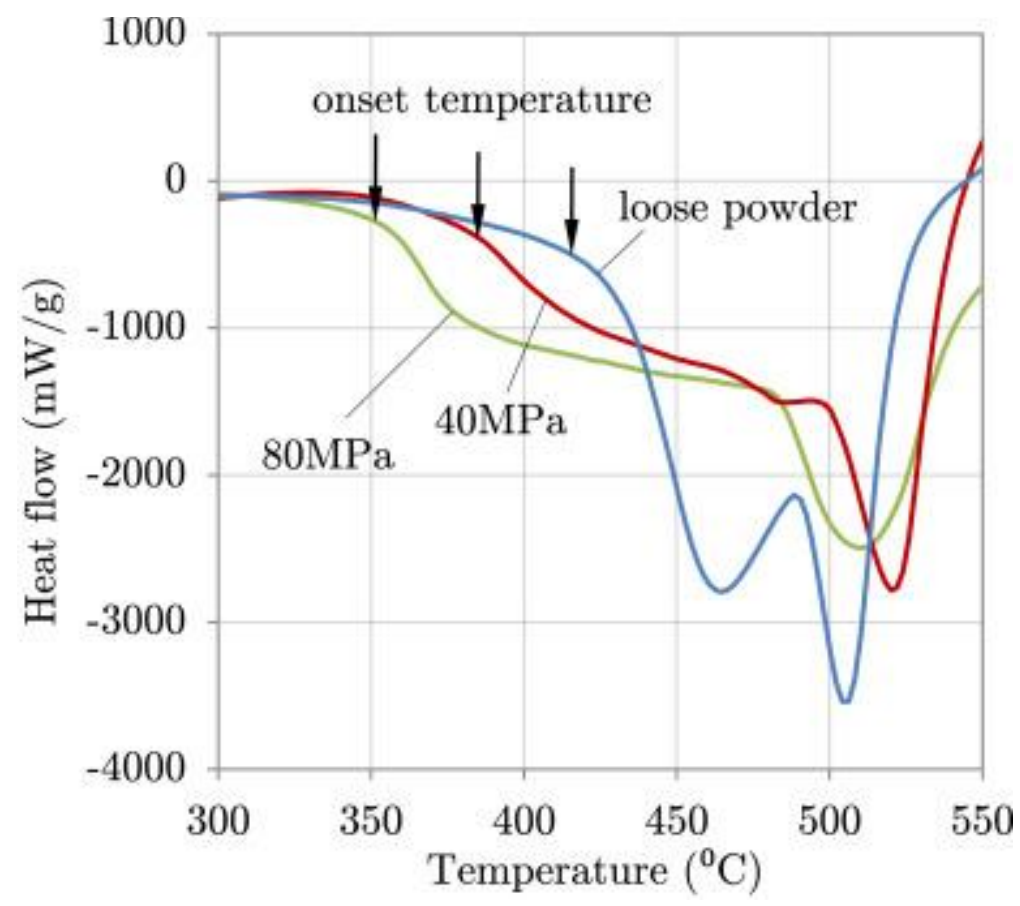

Fig. 4. DSC of $\mathrm{TiH}_{2}$ powder ball milled for $180 \mathrm{~min}(1.0 \mu \mathrm{m})$ and cold compacted under 0, 40 and $80 \mathrm{MPa}$.

This $\mathrm{TiH}_{2}$ powder, as well as commercial titanium powder, is used pure or mixed with commercial aluminium. Mixing is done in a turbula 3D mixer at $50 \mathrm{rpm}$ for $30 \mathrm{~min}$. The aluminium content was varied from 0 to 50 at $\%$.

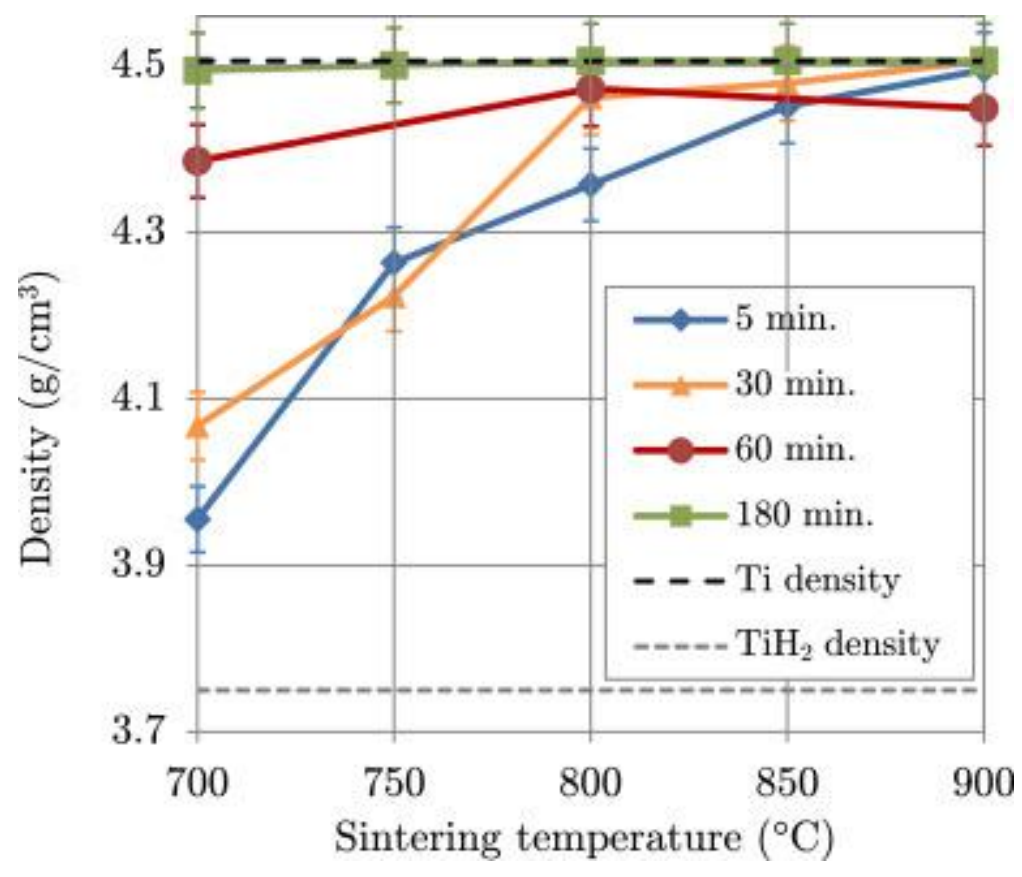

Fig. 5. Density of sintered ball milled $\mathrm{TiH}_{2}$ as a function of sintering temperature. 
A vacuum hot press induction furnace is used to perform sintering under primary vacuum $\left(10^{-2} \mathrm{mbar}\right)$. The mould is machined from graphite, of inside diameter $6 \mathrm{~mm}$ and outside diameter $25 \mathrm{~mm}$, and height $30 \mathrm{~mm}$. The mould is lined with graphite paper to aid removal of the sample. The temperature is measured using a thermocouple positioned inside the mould. The temperature is varied from 700 to $900{ }^{\circ} \mathrm{C}$, reaching holding temperature after 3-5 min, and the pressure and time fixed at $80 \mathrm{MPa}$ and $30 \mathrm{~min}$ respectively.

\subsection{Characterisation}

The particle size distribution of $\mathrm{TiH}_{2}$ powder is measured by laser granulometry using a Mastersizer 2000 using distilled water as a liquid media. The powders are dispersed in the water by applying ultrasound. Visual study of the powders and microstructural and phase analysis of the sintered specimens were performed using SEM and Energy Dispersive Spectroscopy (EDS) using a TESCAN VEGA SEM. The desorption kinetic of hydrogen from $\mathrm{TiH}_{2}$ was measured by DSC using a Setaram Sensys Evo, where the endothermic reaction is measured under a constant heating rate of $10 \mathrm{~K} / \mathrm{min}$. Approximately $23 \mathrm{mg}$ of loose or cold compacted powder was heated up to $580^{\circ} \mathrm{C}$ under a flow of argon. The hydrogen content is qualitatively quantified by measuring the remaining amount of $\mathrm{TiH}_{2}$ phase by XRD full pattern matching evaluation using EVA and are verified quantitatively by the CHNS-O combustion technique. The hardness of sintered specimens is measured by indention using a Wilson Vickers Hardness tester, model 452 SVD, with a force of $5 \mathrm{~kg}$ and dwell time of $5 \mathrm{~s}$.

\section{Results and discussion}

\subsection{Ball milled powders}

Table 1 shows the mode particle size (by volume) of the $\mathrm{TiH}_{2}$ powders ball milled of different durations. The particle size reduced from $6.6 \mu \mathrm{m}$ after $5 \mathrm{~min}$ of ball milling to $1.0 \mu \mathrm{m}$ after $180 \mathrm{~min}$ of ball milling. The reduction in size is confirmed by SEM micrographs presented in Fig. 2. The tendency of finer powders to form agglomerations is also visible.

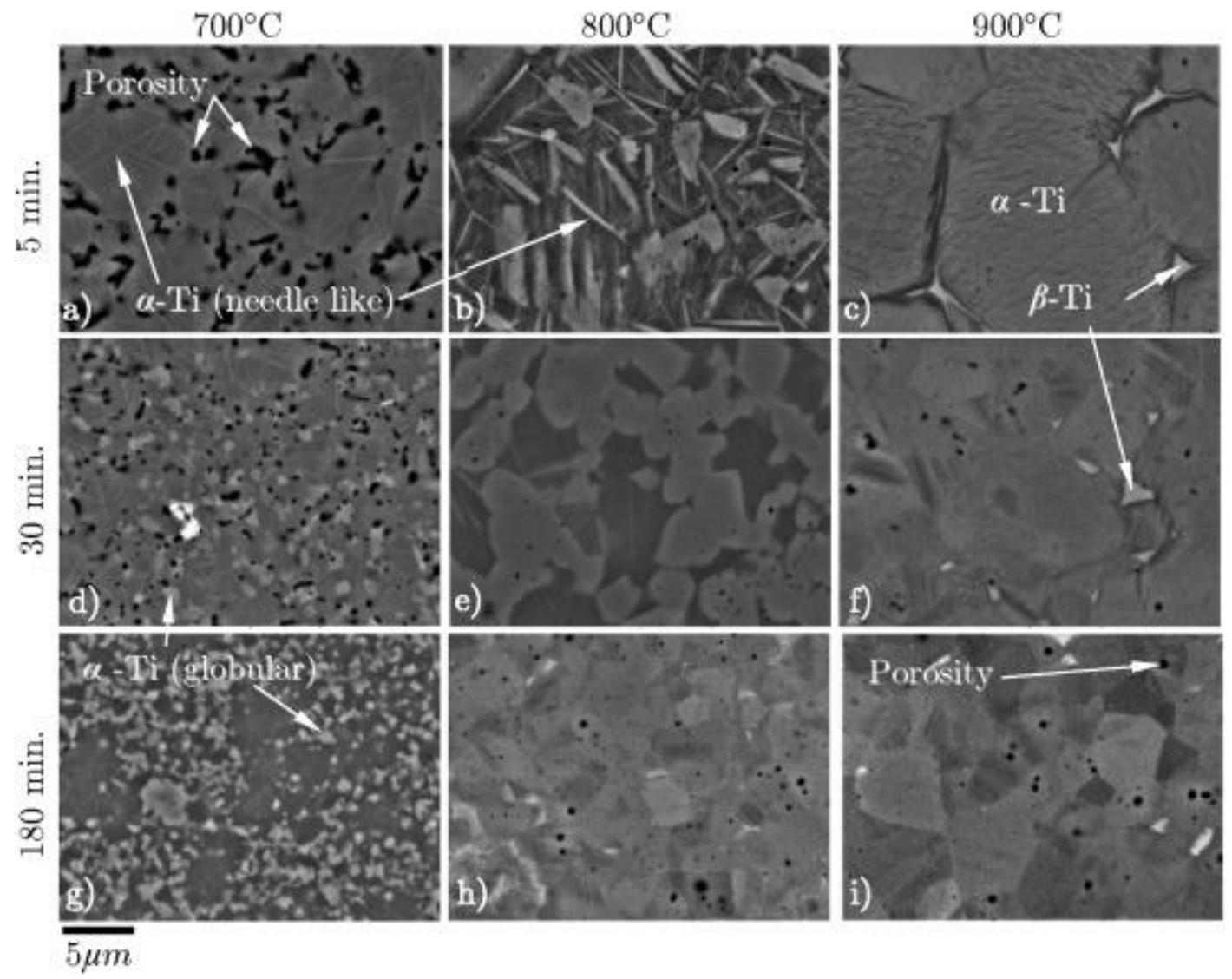


Fig. 6. SEM micrographs (BSE) of sintered $\mathrm{TiH}_{2}$ powders, ball milled 5, 30 and 180 min, aligned horizontally, sintered at 700, 800 and $900^{\circ} \mathrm{C}$, arranged vertically, under $80 \mathrm{MPa}$ for $30 \mathrm{~min}$.

To predict the behaviour of the powders during sintering, DSC analyses are carried out on the ball milled $\mathrm{TiH}_{2}$ (Fig. 3). The dehydrogenation process occurs in two steps [25]: (1) $\gamma$ - $\mathrm{TiH}_{2(1.92)}$ transforms to $\mathrm{TiH}_{(0.7-1.1)}$, then (2) $\mathrm{TiH}_{(0.7-1.1)}$ transforms to $\alpha$-Ti. Powder ball milled for 5 min shows a single peak at $550{ }^{\circ} \mathrm{C}$. Here, the two stages of dehydrogenation are combined in a single peak. For powders milled for 60 and 180 min, two peaks are shown and are seen to initiate at lower temperatures for longer ball milled powders, as previously seen [17], [25]. The decrease in dehydrogenation temperature is suggested to be caused by the decrease of particle size and the increase of defect density. The separation of the peaks is caused by the higher thermal stability of the $\delta-\mathrm{TiH}_{(0.7-1.5)}$ phase in the second stage of dehydrogenation. The ball milling induces the earlier initiation of desorption upon heating and the increased separation of the peaks.

More DSC experiments were performed to investigate the desorption of hydrogen under different compaction pressures. Fig. 4 shows the dehydrogenation of $\mathrm{TiH}_{2}$ ball milled for $180 \mathrm{~min}$, and cold compacted at 0 (loose powder), 40 and $80 \mathrm{MPa}$. The temperature of the first stage of dehydrogenation is seen to decrease with an increase of compaction pressure, while the overall duration of the desorption is increased. Cold compaction increases contact between particles, enabling the direct transfer of heat, which leads to easier heating and causes the overall dehydrogenation to occur, while the rate of dehydrogenation is reduced (because of the increased density acting as another barrier for hydrogen).

The relatively large endothermicity of the hydrogen desorption must be considered. This phenomenon indicates that the desorption of hydrogen requires energy to be consumed locally by the particles which will create temporary negative temperature gradients around the particles during sintering, which will affect it locally.

\subsection{Sintering and characterisation of dense samples}

Fig. 5 shows the density of the sintered $\mathrm{TiH}_{2}$ powders ball milled at different durations as a function of their sintering temperatures. This figure shows that the sintered density increases with both ball milling duration and sintering temperature as expected. At $700^{\circ} \mathrm{C}$, an increase in ball milling duration from 5 to 180 min renders fully dense titanium. 


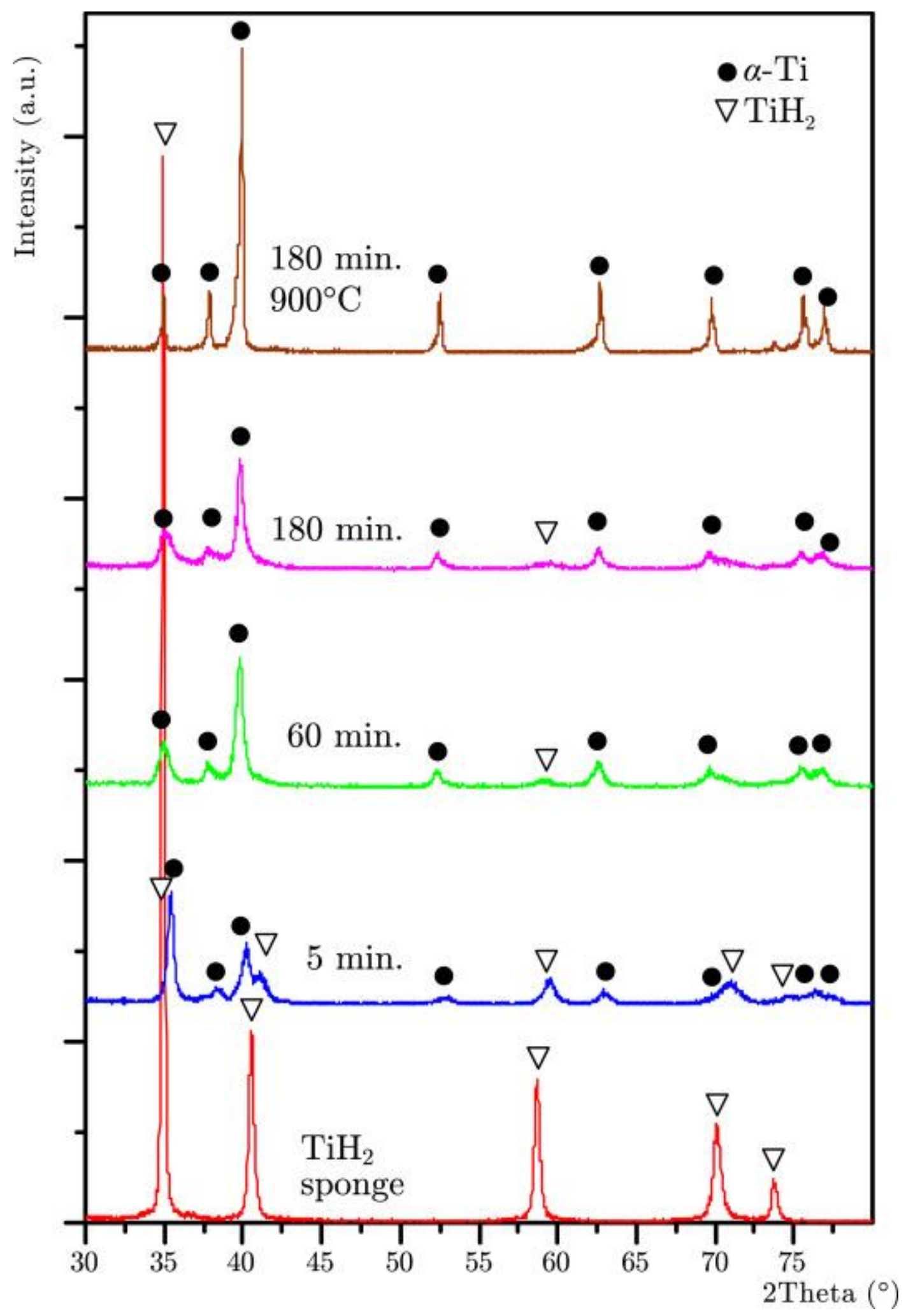

Fig. 7. XRD patterns of $\mathrm{TiH}_{2}$ sponge, and ball milled for 0, 5, 60 and $180 \mathrm{~min}$ sintered at $700{ }^{\circ} \mathrm{C}$, and also ball milled for $180 \mathrm{~min}$ and sintered at $900^{\circ} \mathrm{C}$, for 30 min under $80 \mathrm{MPa}$.

The main effect of ball milling is to decrease the particle size. The surface of the $\mathrm{TiH}_{2}$ particle (unbonded atomic array) has a greater energy than its bulk (i.e. a higher surface energy), which promotes the formation of a bulk. Thus a finer powder, with a longer ball milling duration, densifies easier than a coarse one. 
The pore structure, grain size, and the phase distribution of the sintered $\mathrm{TiH}_{2}$ powders are analysed by SEM (Fig. 6). Pure $\alpha$-Ti appears as the lighter phase while the darker phase is $\mathrm{TiH}_{2}$. Several features can be observed in Fig. 6:

1. Regardless of the ball milling time, grain size increases when sintering temperature increases.

2. Regardless of the sintering temperature, grain size decreases when ball milling time increases.

3. Porosity levels seem to decrease when sintering temperature increases, and agree with the measured densities (Cf Fig. 5).

4. A small volume of spherical pores appears with increased ball milling duration and sintering temperature. This is suggested to be caused by indiffusable gases, such as $\mathrm{N}_{2}$ or $\mathrm{O}_{2}$, which increased in quantity in powders ball milled for longer durations, and became volatile at higher temperatures.

5. A needle like structure of $\alpha-\mathrm{Ti}$ is mostly observed from ball milling time of $5 \mathrm{~min}$, whereas globular $\alpha$-Ti is observed at larger milling times (60 and $180 \mathrm{~min}$ ). $\alpha$-Ti needle grains are formed first because of their HCP structure. Then, the grains grow to become more globular. Ball milling reduces the dehydrogenation temperature of $\mathrm{TiH}_{2}$, and so reduces the temperature of the formation of $\alpha$-Ti needles issued from the dehydrogenation of $\mathrm{TiH}_{2}$ during sintering. Thus, increased ball milling durations allow the more advanced formation of globular grains.

6. At higher temperatures $\left(900^{\circ} \mathrm{C}\right) \beta$-Ti is observed at the $\alpha$-Ti grain boundaries.

Fig. 7 shows the XRD patterns of loose $\mathrm{TiH}_{2}$ sponge and the sintered ball milled $\mathrm{TiH}_{2}$ as a function of ball milling duration, indexed using ICDD numbers 044-1294 and 025-0983 for $\alpha$-Ti and $\mathrm{TiH}_{1.924}$ respectively. The most isolated $\mathrm{TiH}_{2}$ peak at $2 \theta=58^{\circ}$ shows clearly the decrease of $\mathrm{TiH}_{2}$ content with ball milling duration, confirming the previous SEM micrographs. Density, SEM and XRD measurements indicate the increase in densification and dehydrogenation during sintering as a consequence of ball milling duration (e.g. reduction of particle size and increase in lattice defects).

Fig. 7 also presents the XRD patterns of the material prepared from $\mathrm{TiH}_{2}$ ball milled for 180 min and sintered at $900^{\circ} \mathrm{C}$. The increase in sintering temperature allows further elimination of hydrogen. The grain size increases with temperature, indicated by the narrowing of the $\alpha$-Ti diffraction peaks.

The hardness of sintered $\mathrm{TiH}_{2}$ specimens are shown in Fig. 8. Hardness is increased both when the starting powder size decreases and when the sintering temperature increases. The increase of hardness with temperature mimics the evolution of the density as a function of temperature (Cf Fig. 5). The hardness values are relatively high, up to $600 \mathrm{HV}$, when compared to the hardness of pure titanium of $145 \mathrm{HV}$ of ASM titanium Grade 2, and 101 HV5 of titanium sponge densified by melting. The hardness of sintered titanium is influenced by (i) the remaining $\mathrm{TiH}_{2}$, (ii) the remaining interstitial impurities, (iii) grain size and (iv) the amount of porosity. 


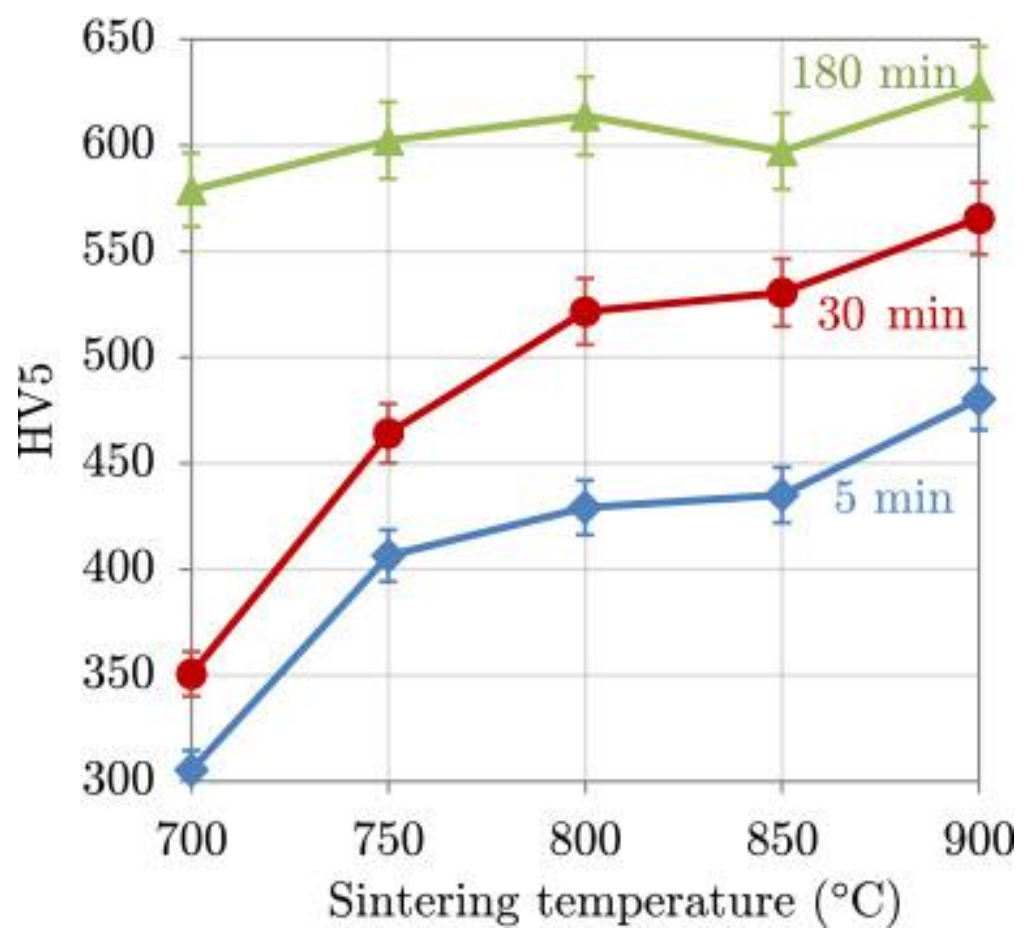

Fig. 8. Hardness of sintered $\mathrm{TiH}_{2}$ ball milled for 5, 30 and $180 \mathrm{~min}$.

It is likely that increased oxygen pick up, due to powder size reduction, causes increasing hardness with milling time, while the increase in hardness with sintering temperature is due to increased density. Hydrogen is eliminated by increasing sintering temperature, as seen by XRD ( $\mathrm{Cf}$ Fig. 7), indicating that remaining interstitial hydrogen does not significantly contribute to the high hardness. Solid $\mathrm{TiH}_{2}$ is significantly lower in hardness than $\alpha-\mathrm{Ti}$ [31], and then reduces the hardness of sintered specimens if not eliminated. It contributes to the increasing hardness seen with increased sintering temperature and ball milling duration. However, it is worth pointing out that the total elimination of $\mathrm{TiH}_{2}$ cannot have caused hardness values above that of $\alpha$-Ti.

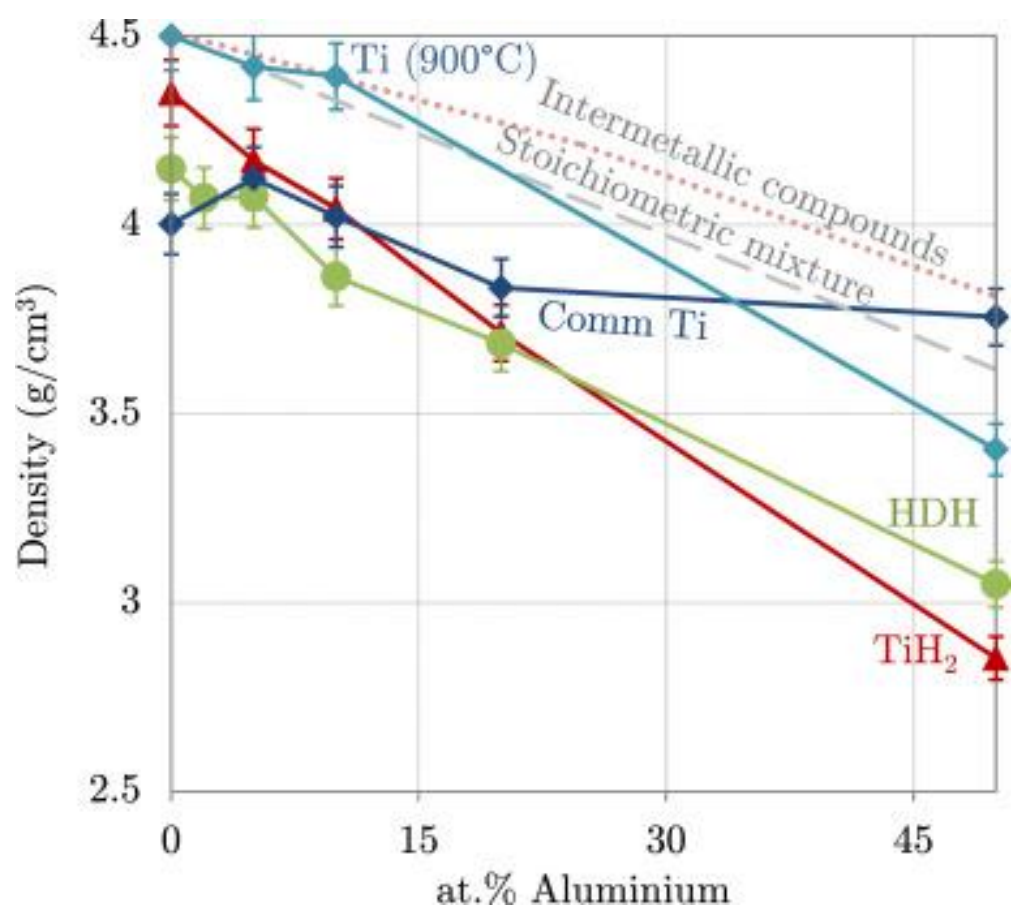

Fig. 9. Densities of commercial titanium, ball milled $\mathrm{TiH}_{2}$ and $\mathrm{HDH}$ powders with aluminium added. 

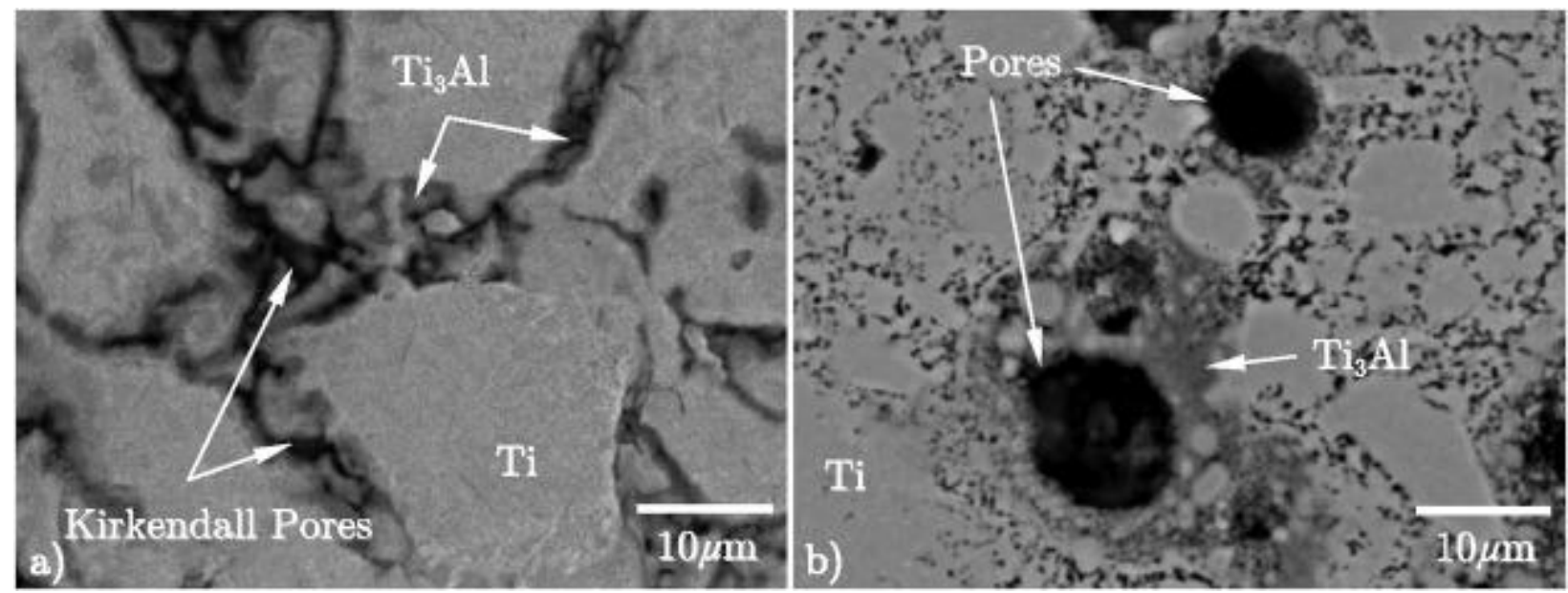

Fig. 10. Microstructure of commercial Ti (a) and $\mathrm{HDH}(\mathrm{b})$ with 10 at $\%$ Al sintered at $700{ }^{\circ} \mathrm{C}$ for $30 \mathrm{~min}$ under $80 \mathrm{MPa}$.

Other impurities, such as $\mathrm{C}, \mathrm{N}$, and $\mathrm{O}$, increase the hardness of titanium. These interstitial elements create distortions inside the crystal lattice which impede the motion of dislocations, leading to strengthening and hardening. The surface of $\mathrm{TiH}_{2}$ particles is coated with an oxide layer [32], and the reduction of particle size increases the specific surface area, and therefore the relative amount of oxygen in a powdered material. The increased oxygen concentration from mechanical milling has already been reported previously to cause an increase in hardness [4], [33].

\subsection{Ball milled titanium with aluminium}

Ball milling of $\mathrm{TiH}_{2}$ leads to faster densification and dehydrogenation during sintering while reducing the final grain size. The second stage of this study was to observe the effect of ball milling on the interaction of aluminium with titanium during blended elemental sintering. Ball milled $\mathrm{TiH}_{2}$ is compared to a larger commercial titanium powder to study the effect of reduced powder size on the reaction between liquid aluminium and titanium. As well as $\mathrm{TiH}_{2}$ ball milled for $180 \mathrm{~min}$, a dehydrogenated ball milled $\mathrm{TiH}_{2}$ (i.e. Hydride De-Hydride powder, called $\mathrm{HDH}$ in the following) is tested in order to eliminate the effects of hydrogen during sintering. As we report that dehydrogenation is incomplete when sintered at $700{ }^{\circ} \mathrm{C}$, the remaining $\mathrm{H}_{2}$ exiting from $\mathrm{TiH}_{2}$ can be trapped into liquid aluminium or titanium aluminides causing embrittlement. The $\mathrm{HDH}$ powder was made from $\mathrm{TiH}_{2}$ ball milled for $180 \mathrm{~min}$. Dehydrogenation was performed in primary vacuum $\left(10^{-2} \mathrm{mbar}\right)$ at $500^{\circ} \mathrm{C}$ for $3 \mathrm{~h}$. Through XRD analysis, the final powder was pure $\alpha-\mathrm{Ti}$.

\subsubsection{Density}

Fig. 9 shows a comparison of the sintered densities of $\mathrm{HDH}, \mathrm{TiH}_{2}$, and commercial titanium powder mixed with $0-50$ at $\%$ aluminium, sintered at $700{ }^{\circ} \mathrm{C}$ for $30 \mathrm{~min}$ under $80 \mathrm{MPa}$. Such conditions allow (i) full densification for ball milled powders when no aluminium is added and (ii) the formation of a liquid aluminium phase. The densities are compared to the theoretical one of (i) an un-reacted mixture of titanium and aluminium (dashed line), and (ii) intermetallic compounds formed by complete reactions ( $\mathrm{Ti}_{3} \mathrm{Al}, \mathrm{TiAl}$, $\mathrm{TiAl}_{2}$ and $\mathrm{TiAl}_{3}$ ) (joined by a dotted line). An intermetallic compound will have a higher density than an unreacted mixture due to increased atomic packing. As can be seen on Fig. 9 , the addition of 5 at $\%$ aluminium caused an increase in densification to commercial titanium, and further addition of aluminium decreased densification. For commercial titanium powder sintered at $900{ }^{\circ} \mathrm{C}$, also shown in Fig. 9 , the density is improved by the addition of 10 at $\%$ aluminium. Any addition of aluminium to ball milled titanium powders 
(both $\mathrm{TiH}_{2}$ and $\mathrm{HDH}$ ) caused a decrease of the density. The density of $\mathrm{TiH}_{2}$ and $\mathrm{HDH}$ powders approximately follow the same trend with the addition of aluminium.

\subsubsection{Microstructure}

Fig. 10 shows the microstructure of both commercial titanium powder and HDH powder, sintered with 10 at $\%$ aluminium at $700{ }^{\circ} \mathrm{C}$ for 30 min under $80 \mathrm{MPa}$. Fig. 10a shows that the aluminium has melted between the titanium particles and begun reaction and diffusion forming a skeleton of $\mathrm{TiAl}_{3}$ around the titanium particles, and leaving Kirkendall pores. Fig. 10b shows large spherical pores with adjacent areas of intermetallics surrounding smaller titanium particles. Here, the aluminium has melted and diffused with the surrounding $\mathrm{HDH}$ titanium powder and formed a solid skeleton of intermetallics around the site of the aluminium particle. The smaller particle size of the HDH powder has increased specific surface area, increasing the local interaction of liquid aluminium and solid titanium.

Fig. 11a shows the microstructure, and Fig. 11b shows the corresponding EDS line profile, of commercial titanium with 50 at $\%$ aluminium sintered at $900{ }^{\circ} \mathrm{C}$. The increased temperature has increased the rate of diffusion, furthering the formation of intermetallics richer in titanium. Kirkendall pores still remain surrounding the titanium particles where the liquid aluminium has been. Our observation is in agreement with the schematic illustration (Fig. 1) of the diffusion of aluminium into titanium.

\subsubsection{XRD phase analysis}

Fig. 12, Fig. 13 show the evolution of phases formed by sintering HDH and commercial titanium powder respectively, with the increase of added aluminium, sintered at $700{ }^{\circ} \mathrm{C}$ for 30 min under $80 \mathrm{MPa}$. The indexed phases are $\mathrm{Ti}_{3} \mathrm{Al}, \mathrm{TiAl}, \mathrm{TiAl}_{2}, \mathrm{TiAl}_{3}$, and aluminium (ICDD 052-0859, 005-0678, 052-0861, 052-0859 and 0011180 respectively). It allows the observation of the diffusion of titanium and liquid aluminium (as described in Fig. 1). The first intermetallic to form, $\mathrm{TiAl}_{3}$, forms rapidly around the surface of the titanium particles, until the liquid aluminium is consumed. Then, titanium and $\mathrm{TiAl}_{3}$ diffuse to form phases richer in titanium. For both the commercial titanium and $\mathrm{HDH}$ powders, at 10 at \% aluminium the intermetallic phase seen is $\mathrm{Ti}_{3} \mathrm{Al}$. The stages of diffusion described are completed, and further diffusion will lead to solid solution of aluminium in titanium. For an increased aluminium concentration of 50 at \%, a range of intermetallics are seen for both commercial and $\mathrm{HDH}$ powders. $\mathrm{TiAl}_{3}$ is seen to remain in larger concentrations for the $\mathrm{HDH}$ powder, indicating incomplete diffusion. With a finer ball milled powder, the liquid aluminium has been able to consume titanium particles and form $\mathrm{TiAl}_{3}$, leaving no solid titanium at the centre of the particle to diffuse further. 


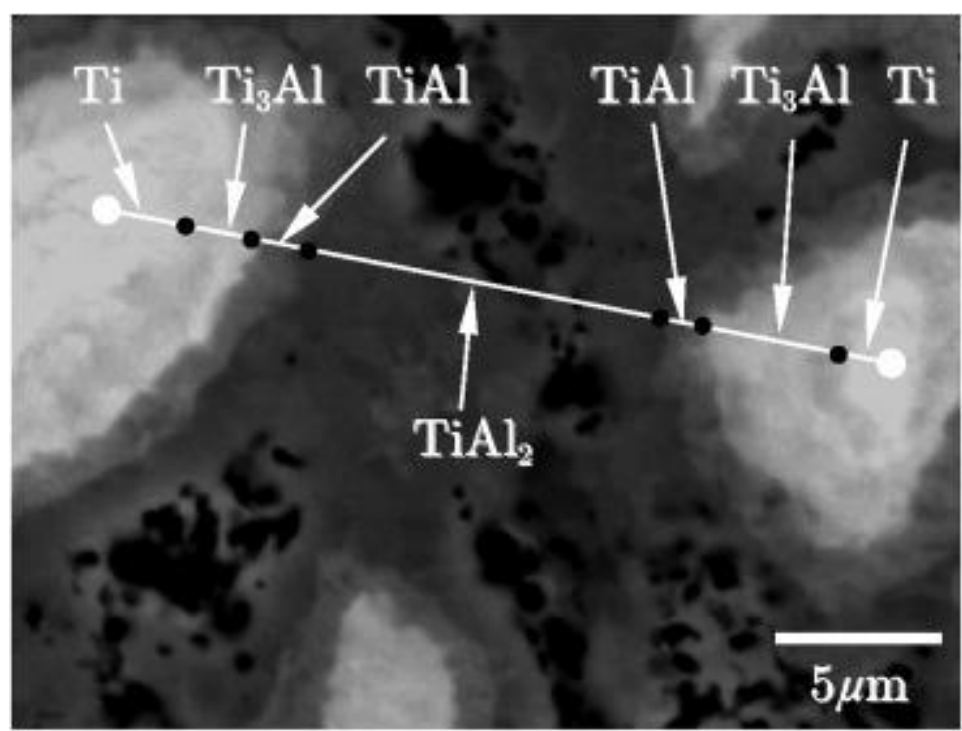

(a)

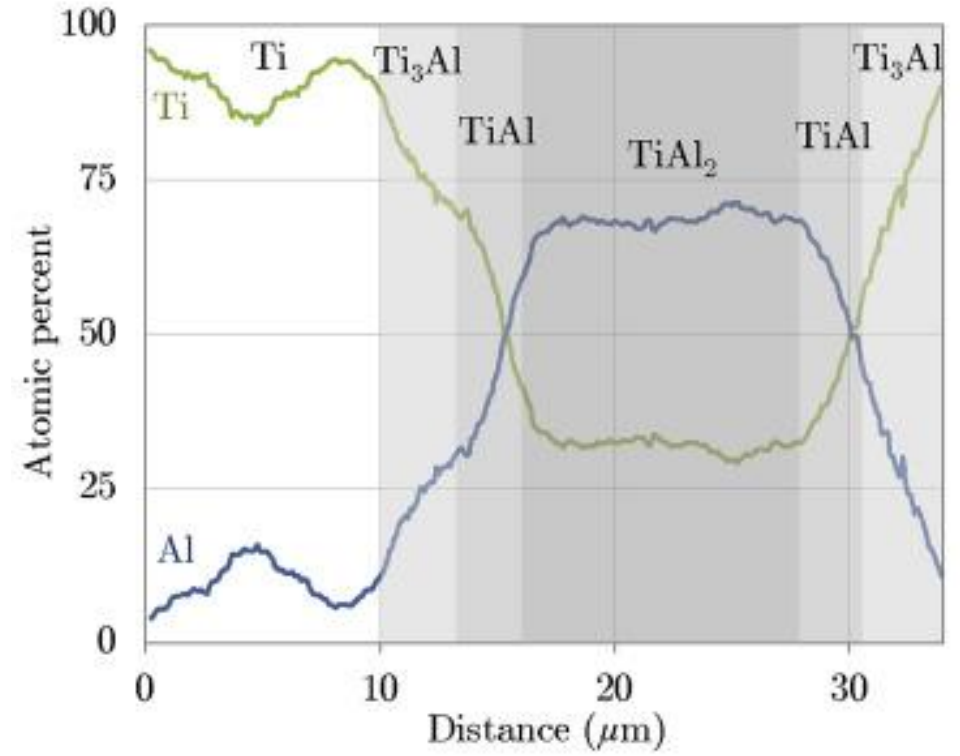

(b)

Fig. 11. (a) SEM micrograph and (b) EDS elemental line profile of commercial Ti mixed with $50 \%$ aluminium sintered at $900{ }^{\circ} \mathrm{C}$ under $80 \mathrm{MPa}$ for $30 \mathrm{~min}$. 


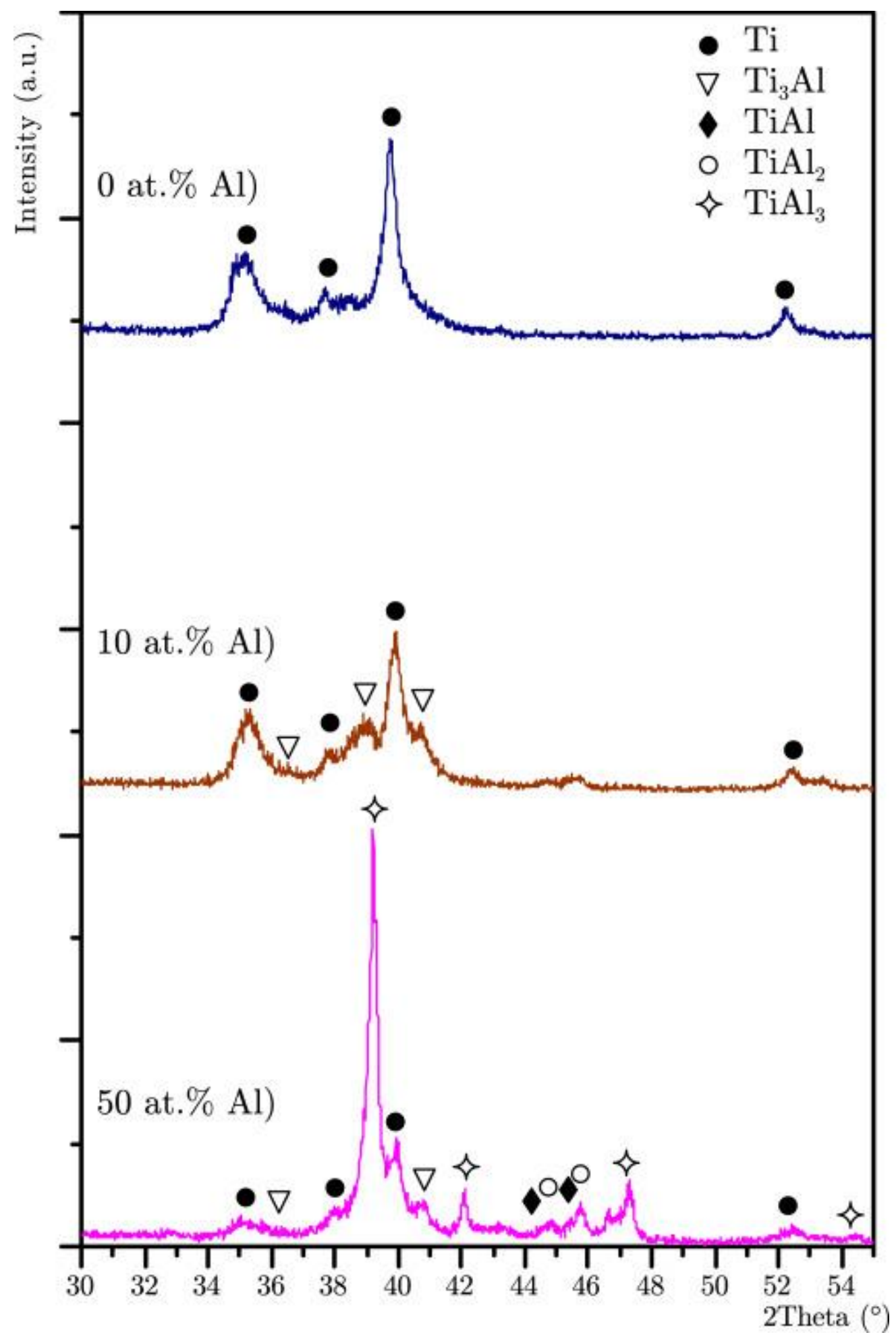

Fig. 12. XRD patterns of HDH ball milled for $180 \mathrm{~min}$, blended with 0, 10 and 50 at $\%$ Al and sintered at $700{ }^{\circ} \mathrm{C}$ for 30 min under $80 \mathrm{MPa}$. 


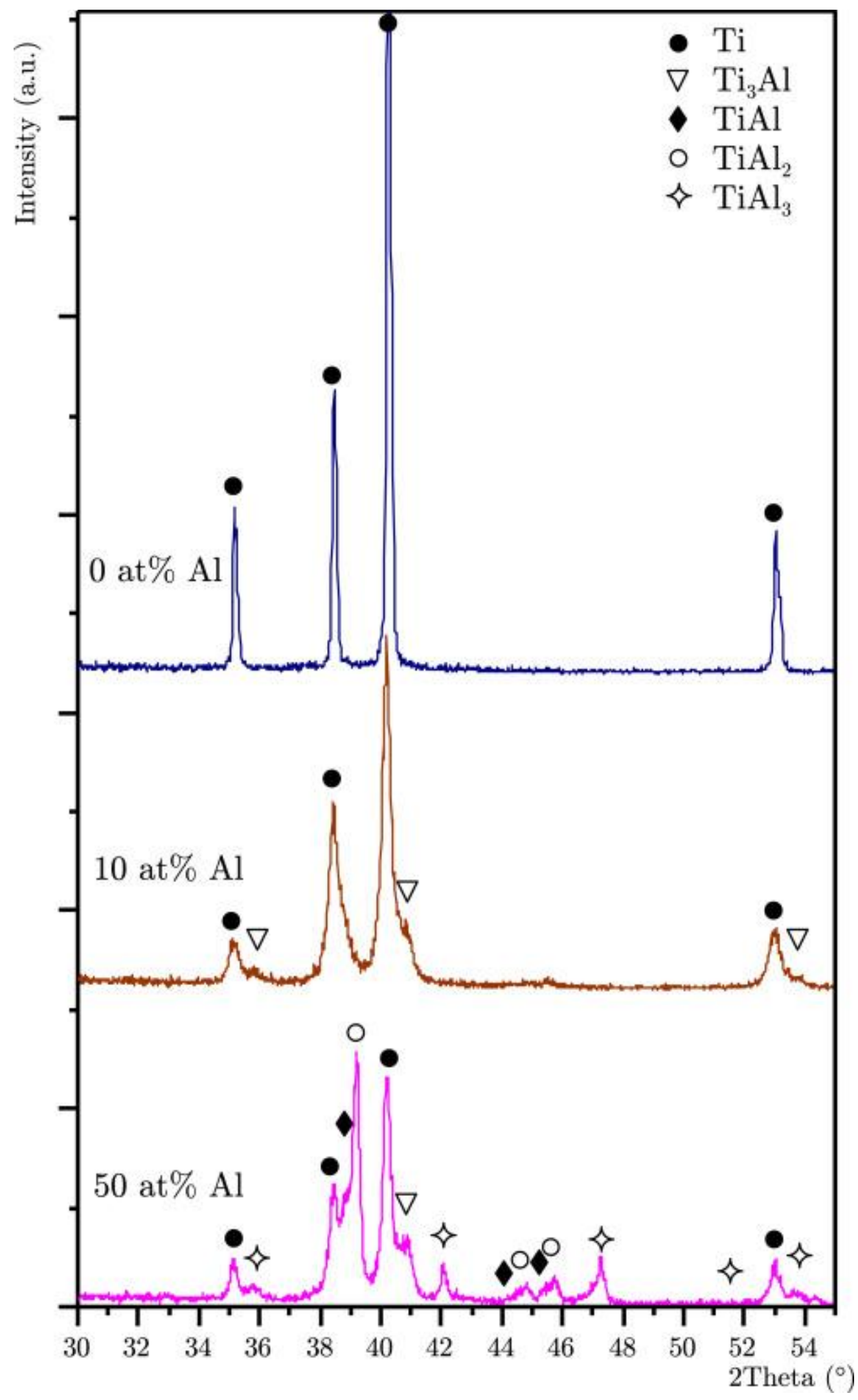

Fig. 13. XRD patterns of commercial Ti, blended with 0,10 and 50 at $\%$ Al and sintered at $700{ }^{\circ} \mathrm{C}$ for 30 min under $80 \mathrm{MPa}$.

\subsubsection{High concentration of aluminium}

In order to study the interaction of titanium and liquid aluminium, large concentrations (i.e. larger than conventionally used in titanium alloys) of aluminium have been used. Fig. 14 shows the microstructure of both commercial titanium powder (a) and $\mathrm{HDH}$ powder (b), sintered with 50 at\% aluminium at $700{ }^{\circ} \mathrm{C}$ for 
30 min under $80 \mathrm{MPa}$. The higher concentration of aluminium with commercial titanium has caused increased densification by a rearrangement of titanium particles, although not without porosity caused by the Kirkendall effect. Increased aluminium concentration, in the case of the finer HDH powder, has increased the distribution of intermetallics, however the aluminium particle sites remain as pores.
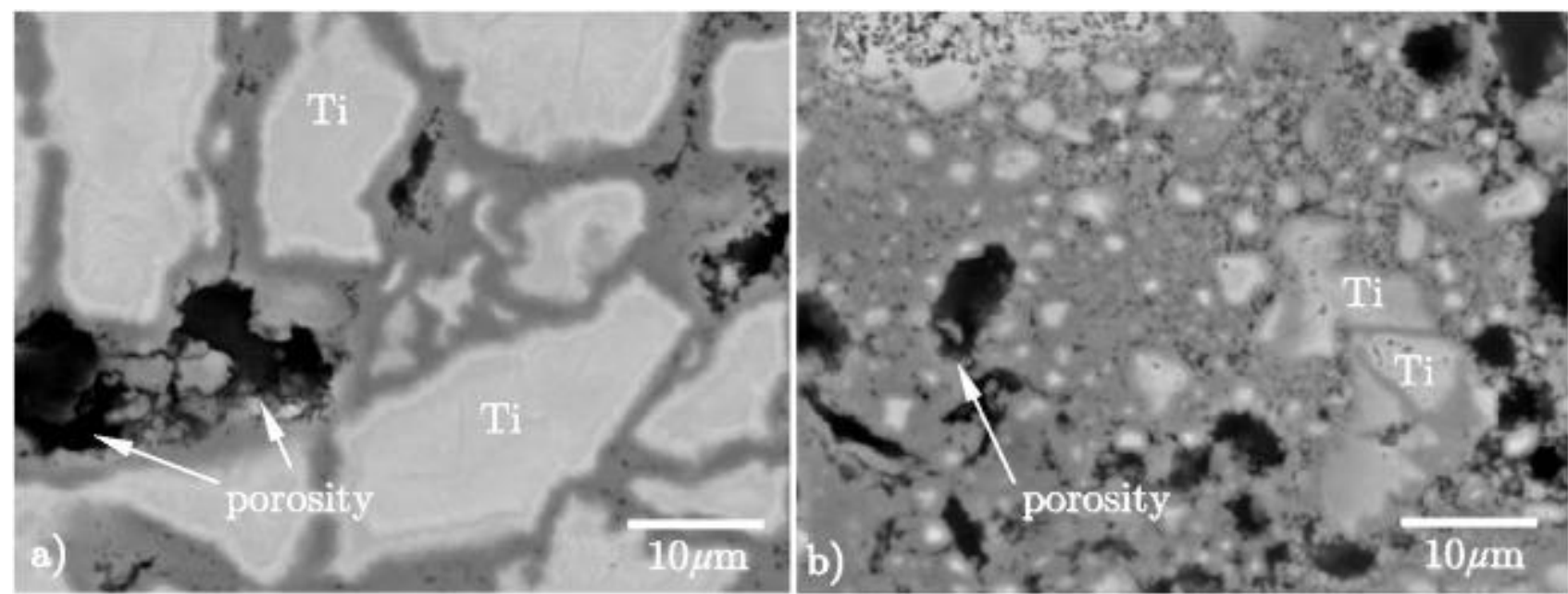

Fig. 14. Microstructures of sintered commercial (a) and $\mathrm{HDH}(\mathrm{b})$ with 50 at $\%$ Al sintered at $700{ }^{\circ} \mathrm{C}$ for 30 min under $80 \mathrm{MPa}$.

\subsubsection{Discussion of ball milled powders with luminium}

The differences of densification between the ball milled powders ( $\mathrm{TiH}_{2}$ and $\mathrm{HDH}$ ) and the commercial powders lie in their different size and morphology. Diffusion between solid titanium and liquid aluminium starts at the surface of the titanium particle. The increased specific surface area of the finer ball milled powders increases the area at which the diffusion can take place, thus diffusion occurs faster. The reaction between liquid aluminium and solid commercial titanium powder is slowed by the increased size of the particles, and the liquid aluminium is able to surround the commercial titanium particles to encourage rearrangement and densification. The $\mathrm{HDH}$ powder reacts faster with liquid aluminium, then pores are created and are surrounded by intermetallics at the sites where the aluminium particles were. A study by Savitskii and Burtsev [30] showed that the increase in titanium particle size above $45 \mu \mathrm{m}$ caused additional swelling because of the stress in the solid intermetallic layer that grows around the titanium particles. This present study uses a finer titanium powder (e.g. $1.0 \mu \mathrm{m}$ ) and it is seen that a decreased particles size acts to decrease density. Thus, the increased reaction rate between fine titanium particles and liquid aluminium decreases densification.

Importantly, it is observed in this study that, with pressure assistance, increased densification can occur using aluminium LPS (see Fig. 9). Commercial titanium powder showed an increase in density with 5 at \% aluminium sintered at $700{ }^{\circ} \mathrm{C}$ under $80 \mathrm{MPa}$ for $30 \mathrm{~min}$, and a fully dense specimen was achieved when sintering with 10 at $\%$ aluminium at $900{ }^{\circ} \mathrm{C}$ (see Fig. 9). With commercial titanium powder, the liquid aluminium is able to surround the titanium particles, whereas for finer ball milled powders, this did not occur. In previous studies [8], [27], the use of aluminium in LPS caused a reduction in density during free sintering. The diffusion between liquid aluminium and solid titanium caused the formation of pores, known as the Kirkendall effect. However, we have found that full densification is possible using LPS through pressure assisted sintering for aluminium concentrations lower than 10 at\%.

\section{Conclusion}


In this study, $\mathrm{TiH}_{2}$ was ball milled to form a fine powder which was seen to give faster dehydrogenation, higher densification and a finer grain size after sintering. DSC experiments showed that dehydrogenation occurs faster and at lower temperatures with increased ball milling duration. The increase of ball milling duration from 5 to $180 \mathrm{~min}$ enabled full densification by hot press sintering at $700{ }^{\circ} \mathrm{C}$ under $80 \mathrm{MPa}$ for 30 min. However, the impurities introduced during ball milling, induced by the larger specific surface area, is likely to cause the sintered samples increased hardness.

The effect of a fine ball milled powder on the interaction of aluminium with titanium during blended elemental sintering was studied. Ball milled powders were compared with commercial titanium powders, with the addition of various concentrations of aluminium. The initial diffusion of liquid aluminium and solid titanium, leading to the formation of $\mathrm{TiAl}_{3}$, gives rise to Kirkendall pores. Then titanium and $\mathrm{TiAl}_{3}$ diffuse to give phases richer in titanium. Increased densification was obtained with the addition of 5-10 at \% aluminium with larger commercial titanium powders, where liquid aluminium filled pores and aided particle rearrangement. The finer titanium particles produced by ball milling react with aluminium to form titanium aluminides in a skeleton structure locally around the aluminium particle site, leading to a porous microstructure.

\section{Acknowledgements}

The authors thank Mr. E. Lebraud, Mrs. L. Etienne and Dr. N. Penin for their technical assistance and Region Aquitaine for its financial support.

\section{References}

[1] K. Faller, F. Froes. The use of titanium in family automobiles: current trends. JOM, 53 (2001), pp. 27-28.

[2] S. Gerdemann. Titanium process technologies. Adv. Mater. Process., 159 (2001), pp. 41-43.

[3] W. Kroll. The production of ductile titanium. J. Electrochem. Soc., 78 (1940), pp. 35-47.

[4] O. Ivasishin, D. Savvakin, F. Froes, V. Mokson. Synthesis of alloy Ti-6Al-4V with low residual porosity by a powder metallurgy method. Powder Metall. Metal Ceram., 41 (2002), pp. 7-8.

[5] O. Ivasishin, A. Demidik, D. Savvakin. Use of titanium hydride for the synthesis of titanium alumides from powder materials. Powder Metall. Metal Ceram., 38 (1999), pp. 9-10.

[6] L. Bolzoni, P. Esteban, E. Ruiz-Navas, E. Gordo. Mechanical behaviour of pressed and sintered titanium alloys obtained from prealloyed and blended elemental powders. J. Mech. Behav. Biomed. Mater., 14 (2012), pp. 29-30.

[7] R. Low, I. Robertson, G. Schaffer. Excessive porosity after liquid-phase sintering of elemental titanium powder blends. Scr. Mater., 56 (2007), pp. 895-898.

[8] Y. Liu, L. Chen, H. Tang, C. Liu, B. Liu, B. Huang. Design of powder metallurgy titanium alloys and composites. Mater. Sci. Eng., A 418 (2006), pp. 25-35.

[9] H. Wang, Z. Fang, P. Sun. A critical review of mechanical properties of powder metallurgy titanium. Int. J. Powder Metall., 46 (2010), pp. 45-57.

[10] C. Azevedo, D. Rodrigues, F.B. Neto. Ti-Al-V powder metallurgy (PM) via the hydrogenationdehydrogenation (HDH) process. J. Alloys Compd., 353 (2003), pp. 217-227.

[11] G. Crowley. How to extract low-cost titanium. Adv. Mater. Process., 161 (2003), pp. 25-27. 
[12] W. Chen, Y. Yamamoto, W. Peter, S. Gorti, A. Sabau, M. Clark, S. Nunn, J. Kiggans, C. Blue, J. Williams, B. Fuller, K. Akhtar. Cold compaction study of strong process Ti-6Al-4V powders. Powder Technol., 214 (2011), pp. 194-199.

[13] C. Doblin, D. Freeman, M. Richards. The TiRO process for the continuous direct production of titanium powder. Key Eng. Mater., 551 (2013), pp. 37-43.

[14] S. Dadbakhsh, M. Speirs, J. Kruth, J.V. Humbeeck. Influence of SLM on shape memory and compression behaviour of NiTi scaffolds. CIRP Ann. Manuf. Technol., 64 (2015), pp. 209-212.

[15] F. Froes. Titanium powder metallurgy: a review - part 1. Adv. Mater. Process., 170 (2012), pp. 16-22.

[16] O. Senkov, F. Froes. Thermo hydrogen processing of titanium alloys. Int. J. Hydrogen Energy, 24 (1999), pp. 565-576.

[17] H. Wang, M. Lefler, Z. Fang, T. Lei, S. Fang, J. Zhang, Q. Zhao. Titanium and titanium alloy via sintering of $\mathrm{TiH}_{2}$. Key Eng. Mater., 436 (2010), pp. 157-163.

[18] A. Pankevich, A. Chertovich, G. Libenson. Production of titanium specimens from a titanium hydride powder by hot pressing. Poroshk. Metall., 2 (1986), pp. 14-18.

[19] D. Savvakin, M. Humenyak, M. Matviichuk, O. Molyar. Role of hydrogen in the process of sintering of titanium powders. Mater. Sci., 47 (2012), pp. 651-661.

[20] M. Qian. Cold compaction and sintering of titanium and its alloys for near-net-shape or perform fabrication. Int. J. Powder Metall., 46 (2010), pp. 29-44.

[21] H. Sandim, B. Morante, P. Suzuki. Kinetics of thermal decomposition of titanium hydride powder using in situ high-temperature X-ray diffraction (HTXRD). Mater. Res., 8 (2005), pp. 293-297.

[22] H. Okamoto. O-Ti (oxygen-titanium). J. Phase Equilib. Diffus., 32 (2011), pp. 473-474.

[23] O. Ivasishin, D. Savvakin, N. Gumenyak. Dehydrogenation of a titanium-hydride powder and its role in the activation of Sintering. Met. Noveishie Technol., 33 (2011), pp. 899-917.

[24] H. Zhang, E. Kisi. Formation titanium hydride at room temperature by ball milling. J. Phys. Condens. Matter, 9 (1997), pp. L185-L190.

[25] V. Bhosle, E. Baburaj, M. Miranova, K. Salama. Dehydrogenation of $\mathrm{TiH}_{2}$. Mater. Eng., A 356 (2003), pp. 190-199.

[26] S. Asavavisithchai, V. Lopez, A. Kennedy. Non-isothermal decomposition of as-received and oxidised $\mathrm{TiH}_{2}$ powders. Mater. Trans., 48 (2007), pp. 2712-2714.

[27] A. Savitskii, N. Burtsev. Compact growth in liquid phase sintering. Powder Metall. Metal Ceram., 2 (1979), pp. 31-38.

[28] M. Sujata, S. Bhargava, S. Suwas, S. Sangal. On kinetics of $\mathrm{TIA1}_{3}$ formation during reaction synthesis from solid Ti and liquid Al. J. Mater. Sci. Lett., 20 (2001), pp. 2207-2209.

[29] Y. He, Y. Jiang, N. Xu, J. Zou, B. Huang, C. Liu, P. Liaw. Fabrication of dial micro/nanometer-sized porous alloys through the kirkendall effect. Adv. Mater., 19 (2007), pp. 2102-2106.

[30] A. Savitskii, N. Burtsev. Effect of powder particle size on the growth of titanium compacts during liquidphase sintering with aluminium. Powder Metall. Metal Ceram., 20 (1981), pp. 618-621. 
[31] D. Setoyama, J. Matsunaga, H. Muta, M. Uno, S. Yamanaka. Mechanical properties of titanium hydride. J. Alloys Compd., 381 (2004), pp. 215-220.

[32] B. Tsuchiya, S. Nagata, N. Ohtsu, K. Toh, T. Shikama. Thermal desorption of hydrogen at the titanium hydride-oxide interface. Mater. Trans., 46 (2005), pp. 196-198.

[33] L. Bolzoni, E. Ruiz-Navas, E. Neubauer, E. Gordo. Inductive hot-pressing of titanium and titanium alloy powders. Mater. Chem. Phys., 131 (2012), pp. 672-679. 